\section{Edycaçä́

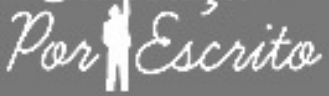

ARTIGO

\section{Editor}

Maria Inês Côrte Vitoria

PUCRS, RS, Brasil

\section{Equipe Editorial}

Pricila Kohls dos Santos

PUCRS, RS, Brasil

Marcelo Oliveira da Silva

PUCRS, RS, Brasil

Carla Spagnolo

PUCRS, RS, Brasil

Rosa Maria Rigo

PUCRS, RS, Brasil

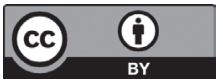

A matéria publicada neste periódico é licenciada sob forma de uma Licença Creative Commons - Atribuição 4.0 Internacional. http://creativecommons.org/licenses/by/4.0/

\title{
(In)Disciplina escolar: desafios e possibilidades aos professores do século XXI
}

School (in)discipline: challenges and opportunities for teachers of the XXI century

\section{Glaé Corrêa Machadoa Mari Margarete dos Santos Forster ${ }^{b}$}

RESUMO: A investigação lida com tensionamentos conceituais, tais como, disciplina/indisciplina, autoridade/ poder/autoritarismo, liberdade/licienciosidade, ordem/desordem, limite/exigência, rigidez/rigor, problematizando-os, confrontando-os ética e epistemologicamente. O referencial teórico tem como base Aquino, Bernstein, Brunner, Correia e Matos, Fischman e Torres, Freire, Foucault, Giorgio, Macedo, Piaget, Silva e Taille. Esse estudo apoiou-se no referencial da pesquisa-ação (Minayo e Thiollent) com professores da Educação Básica do município de Montenegro/RS, que participaram do Projeto de Pesquisa (in)disciplinando a disciplina: processo de construção da prática docente e do cotidiano escolar, parceria entre as Escolas Municipais, a Secretaria Municipal de Educação e a UNISINOS, sendo esta produção parte integrante de nossas considerações sobre o trabalho desenvolvido durante um projeto que durou 03 anos. $O$ estudo analisa as causas geradoras da indisciplina no ambiente escolar, a forma como cada professor procura lidar com a mesma em sua sala de aula e de que maneira os professores estão se preparando para enfrentar o desafio da indisciplina no contexto educacional. Palavras-chaves: Disciplina. Indisciplina. Prática Pedagógica. Escola. Universidade.

ABSTRACT: The research will deal with conceptual tensions, such as discipline/indiscipline, authority/power/ authoritarianism, freedom/licentiousness, order/disorder, limit/requirement, rigidity/rigor, questioning them, confronting them ethically and epistemologically. The theoretical framework is based on Aquino, Bernstein, Brunner, Correia and Matos, Fischman and Torres, Freire, Foucault, Giorgio, Macedo, Piaget, Silva and Taille. This study relied on the action research referential (Minayo and Thiollent) with teachers of basic education in a city of Montenegro/RS, who participated in the Research Project (In)disciplining discipline: construction process of teaching practice and school routine, a partnership between Municipal Schools, the City Department of Education and UNISINOS and this production an integral part of our consideration of the work done during a project that lasted 03 years. The study analyzes the generating causes of indiscipline in the school environment, how each teacher seeks to deal with the same in your classroom and how teachers are preparing to face the challenge of indiscipline in educational context.

Keywords: Discipline. Indiscipline. Pedagogical Practice. School. University.

a Doutoranda em Educação pela PUCRS. Coordenadora Pedagógica da Secretaria Municipal de Educação e Cultura de Montenegro/RS. Professora dos cursos de Pós-Graduação em Educação do UNILASALLE e Faculdades Dom Alberto. <glaemachado@hotmail.com>.

b Doutora em Educação, Professora do Programa de Pós-Graduação em Educação da UNISINOS. <mari.forster@gmail.com> 


\section{Considerações iniciais}

O presente projeto de pesquisa, que tematizou a questão da (in)disciplina escolar, desenvolveu-se junto à rede municipal de ensino de Montenegro, num trabalho com supervisores, orientadores e professores. Apresentou resultados que beneficiam não só a essa rede de ensino, mas também a de outras regiões do Estado, e provocou discussões sobre a formação de professores na Universidade. Quando falamos de disciplina/indisciplina devemos ter em mente um fenômeno complexo, multifacetado e que não encontra sentido único. Esta questão tem ocupado um espaço cada vez maior no cotidiano escolar e vem se tornando um desafio para professores e gestores educacionais e foi estudada pelo grupo de pesquisa, centralmente, sob o enfoque pedagógico, procurando contextualizá-la e entendendo-a no cotidiano da escola, com todos seus rituais e condicionantes, inserida em um espaço-tempo mais amplo: a sociedade brasileira do século XXI.

Vivemos hoje no Brasil, e no mundo, situações de violência, de corrupção, de "desmando", de impunidade que veem tomando conta de todos. A lógica econômico-mercadológica reguladora das ações e das instituições, acrescida das transformações das políticas públicas e do papel do Estado, têm permeado o campo educativo, provocando importantes mudanças na estrutura curricular e na definição dos atores a quem se reconhece com legitimidade para intervir na definição da vida das escolas, na planificação e gestão dos sistemas educativos.

Com a perda da força do Estado que, simbolicamente, pautava a sua intervenção no campo educativo pela lógica do bem público, da preservação da identidade e da cultura nacional, as reformas educativas das décadas de 80 e 90 permitiram a intervenção de outros agentes sociais que interferiram não só nas transformações curriculares, mas na própria concepção de docência. Hoje, com a redução gradativa da intervenção do Estado, os professores, mais do que nunca, têm sido responsabilizados pela crise da nação, dos sistemas educativos, pelo seu despreparo, pela indisciplina dos alunos.

A profissão docente, que encontrava no Estado o princípio de referencialização, é pressionada pelo mercado a se autojustificar permanentemente, gerando para além de uma crise de autoridade, uma crise de poder. Mesmo sabendose que a crise de autoridade dos professores parece ter sido sempre uma das propriedades da profissão e que, como diz Arend (1979), a crise de autoridade consiste, tanto prática como teoricamente, em não se saber o que a autoridade realmente é, vive-se atualmente, e concomitantemente, uma crise dos mecanismos clássicos de delegação de poder nos professores.

Essa discussão foi central nas nossas análises, pois não só nos auxiliou na compreensão da natureza complexa do poder, presente nas relações mais elementares, mais cotidianas, deixando suas marcas nas vidas das pessoas e da sociedade, mas nos possibilitou entendê-lo em suas contradições, como possibilitador ao mesmo tempo de resistências 
e mudanças. Aqui se apresentou uma boa referência para pensar relações particulares na constituição do poder e na própria crítica à autoridade autoritária.

Este enfoque teórico foucaultiano (1993 e 1979), embora muitas vezes niilista-reprodutivo, pode instituir diálogos com Freire, que aposta no poder a serviço da produção de relações sociais mediadoras da materialização da humanidade nos humanos, rejeitando a ideia de poder atrelado ao bom argumento, a razão pura, que se impõe sobre as demais dimensões humanas (FREIRE, 2000, p. 31). Este conjunto de compreensões sobre poder, incitou-nos a indagar: onde está o poder do professor? Correia e Matos (2001, p. 31) indicam que o poder do professor, diferente de sua autoridade, apoia-se em três planos, que estão em crise: plano cognitivo, em que o professor é fiel depositário do saber científico; plano político e social, em que o professor é depositário de um poder cultural, público e laico, delegado pelo Estado-Nação ou por uma geração social e, finalmente, o plano jurídico em que o poder do professor se apoia numa delegação de ordem jurídica que dá legitimidade ao exercício da avaliação que, de um modo geral, não é suscetível de recurso quanto ao seu conteúdo.

Os planos agrupados, caracterizando a "crise de autoridade do professor, constituem [...] uma manifestação da crise dos mecanismos de delegação de poder e dos pressupostos que asseguravam sua ocultação". A crise da delegação cognitiva tem sua origem na "Ciência Moderna, na crise de sua neutralidade axiológica, de sua objetividade, de sua fatualidade e de seu pretenso desinteresse" (2001, p. 32). A crise de autoridade manifesta-se frente à "emergência das incertezas e de imprevisibilidades que já não podem ser encaradas como déficits de cientificidade, mas [...] como dimensões constitutivas do conhecimento científico". Certezas científicas perdem credibilidade. Assim, concluem os autores, (2001, p. 33) "se a crise da delegação cognitiva do poder dos professores se confunde com a crise da própria ciência, a crise da delegação política confunde-se com a crise do próprio Estado e de sua autoridade".

Como já referido anteriormente, a crise de autoridade do professor pode estar diretamente relacionada à crise do Estado, que vem se desresponsabilizando gradativamente de várias atribuições, entre elas, da educação. Os educadores tentam manter seu estatuto original de formadores humanos, enquanto o Estado aponta para novas referências à educação. $\mathrm{O}$ docente, com atribuição da família e do Estado, tem legitimidade enquanto usa o poder delegado. Entretanto, frente a seus alunos esta delegação não é suficiente, pois os coloca em compulsória relação: a escola é local obrigatório para aprender, onde há horários, calendários, trajetos e ritos de obediência a serem cumpridos. O poder do professor, também, é abalado quando o usa para separar os que sabem dos que não sabem, os que acertam e os que erram, potencializando conformismos, competitividade, obediência, por um lado, e resistência, inconformismos, apatias e desobediências, por outro. Assim, a crise da escola moderna acentua-se quando se acentua a crise do paradigma da modernidade. 
Com certeza, dadas às condições atuais, sem o respeito à lei (sem disciplina?) nenhum indivíduo integrase socialmente. Como estimular o indivíduo a "obediência", sem provocar sujeição às autoridades investidas de poder e mando? Como exercer autoridade para produzir liberdade e não o poder pelo poder? A autonomia e não o condicionamento? A responsabilidade e não a submissão? Como ser rigoroso, sem ser rígido? Por que é necessário, possível e legítimo exercer a autoridade e a diretividade sem negar a liberdade de sujeitos envolvidos em processos educativos?

Estas foram algumas das questões que orientaram este estudo e tiveram como marco teórico orientador as reflexões de Paulo Freire. A autoridade freireana é a materialização de relações que se constituem pelo diálogo que os sujeitos envolvidos estabelecem. O poder para Freire aproxima-se do conceito de autoridade que desenvolve: corresponde à capacidade que humanos têm, no diálogo, na aceitação da diferença, problematizar o mundo vivido e a experiência imediata do outro, desafiando à superação do estágio em que se encontra e de sua capacidade de criação e reação.

Vivemos hoje a perda do espaço da escola; os professores, por sua vez, sentem-se, cada vez mais "incompetentes" para dar conta de todas as solicitações, intensificando seu trabalho e regendo-se por uma lógica de consumo dos saberes escolares e de diversificação de públicos que habitam as escolas. Frente a tudo isto e assistindo a violência "explícita como moeda de troca nas relações sociais" ante a violência como "novo código da sociabilidade", é fundamental repensar a função da escola e do educador (OLIVEIRA, 1998, p. 230).

É dentro deste contexto que se fez necessário discutir, também, acerca de questões como autoridade/disciplina/ liberdade. Que autoridade/disciplina/liberdade deve ser desempenhada para auxiliar as pessoas na decifração do mundo? Será a que tem por base a força/ ou a que tem por fundamento a ética, a competência, o diálogo? Como entender e desvelar causas estruturais que provocam marginalização e exclusão? Como perceber a realidade cercada por contradições sócio-históricas, condicionadoras de concepções e práticas de vida? Como construir referenciais que auxiliem na percepção e análise de processos autoritários? Como falar em liberdade hoje, nas condições em que os homens se encontram? Todos estes questionamentos acompanharam a investigação, que partindo dos conceitos e representações de (in)disciplina/autoridade/poder/liberdade dos supervisores, orientadores e professores, sujeitos deste estudo, avançou no sentido de sua problematização, seu tensionamento, sua confrontação ética e epistemológica.

O projeto de pesquisa nos remeteu a reflexões teóricas, tendo como perspectiva um olhar docente sobre a indisciplina no contexto sócio-educacional, o objetivo foi refletir sobre a importância e a contribuição dos vários agentes educacionais (alunos, famílias e a escola) e do papel que exercem nas relações que permeiam o cotidiano escolar. O nosso ponto de partida contempla o movimento dos professores refletindo sobre as causas geradoras das 
situações de indisciplina no ambiente escolar, questionaremos também as formas de lidar com essas situações dentro e fora do contexto educacional, elencamos ainda alternativas e sugestões bem sucedidas para enfrentar o desafio da indisciplina, no intuito de qualificar o trabalho docente.

\section{Caminhos metodológicos}

Conforme Minayo (1994), o objeto das Ciências Sociais é histórico, isto é, as sociedades humanas existem num determinado espaço, cuja formação social e configuração são específicas. Vivem o presente marcado pelo passado e projetado para o futuro, num embate constante entre o que está dado e o que está sendo construído. Portanto, a provisoriedade, o dinamismo e a especificidade são características fundamentais de qualquer questão social. Nas Ciências Sociais existe uma identidade entre sujeito e objeto, pois a pesquisa lida com seres humanos que, por variadas razões, têm um substrato comum de identidade com o investigador. É considerada intrínseca e extrinsecamente ideológica, pois toda ciência é comprometida. Ela veicula interesses e visões de mundo historicamente construídas, embora suas contribuições e seus efeitos teóricos e técnicos ultrapassem as intenções de seu desenvolvimento. Finalmente, o objeto das Ciências Sociais é essencialmente qualitativo.

As orientações metodológicas que adotamos nesse trabalho foram baseadas na perspectiva da pesquisa-ação, ou seja: o pesquisador, não só compartilha do ambiente investigado, mas possibilita que o investigado participe do processo de realização da pesquisa e que os resultados se revertam em benefício do próprio grupo pesquisado. A pesquisa teve um enfoque qualitativo, embasada substancialmente no diálogo freireano. A sustentação teórica considerou estudos sobre a temática (in)disciplina/autoridade/poder/autoritarismo, liberdade/licenciosidade, ordem/ desordem, limites/exigência/rigidez/rigor/, principalmente nas obras de Paulo Freire (2000, 1997, 1996, 1994, 1985, 1982 e 1978)

A pesquisa-ação, na definição de Michel Thiollent (2003, p. 14), é "um tipo de pesquisa social com base empírica que é concebida e realizada em estreita associação com uma ação ou com a resolução de um problema coletivo e no qual os pesquisadores e os participantes representativos da situação ou do problema estão envolvidos de modo cooperativo e participativo".

O objetivo central deste projeto, no diálogo com supervisores, orientadores e professores da rede municipal de Montenegro, foi promover discussões que (re)signifiquem o papel do professor como autoridade pedagógica ética e competente e, ao mesmo tempo, o papel da escola, enquanto espaço formativo. Acredito que, para além de atender a esta rede de ensino, que buscou a parceria espontaneamente para estas discussões, os resultados deste trabalho, juntamente com outras pesquisas já realizadas, poderão se estender não só a outras redes, como às 
Universidades que se ocupam com a formação de professores. Penso que o olhar pedagógico contextualizado pode avançar na compreensão da temática, que tem assumido uma complexidade maior frente aos desafios de nosso tempo.

A discussão sobre o método na pesquisa qualificativa e, especialmente, na pesquisa-ação, é muito rica e sem fim previsível. Trata-se de um grande embate entre correntes distintas de pensamento, como a positivista, a fenomenológica e a dialética, no qual não há vencedores, nem vencidos. Há controvérsias. Cada um tem suas razões e convicções. Um e outro não têm predisposição alguma de ceder em suas posições, já que se fundamentam em paradigmas científicos, ou em concepções e teorias de ciência, que são antagônicos entre si. A discussão toca na questão da cientificidade dos resultados, ou seja, na discussão sobre em que situação investigativa os resultados são confiáveis e válidos, do ponto de vista científico. As questões de fundo são a da objetividade científica, defendida por uns, e na pseudo neutralidade da ciência, apontada por outros. Paulo Freire já disse em 1978 que "toda neutralidade proclamada é sempre uma escolha escondida, na medida em que os temas, sendo históricos, envolvem orientações valorativas dos homens na sua experiência existencial" (1978, p. 89).

A pesquisa-ação, assim como outras modalidades de estudos qualitativos, se concretizam na coleta e análise de dados primários empíricos. Ela se ancora na integração entre o pesquisador e o grupo estudado e dessa relação que depende a captação adequada dos dados. Se eles forem escamoteados, sonegados ou mal compreendidos, toda a pesquisa pode ficar comprometida. Por não se valer de instrumentos mensuráveis, ela implica em menos controle por parte do pesquisador. Na verdade vai depender basicamente da capacidade do investigador em captar, compreender, interpretar e analisar o fenômeno. Esse tipo de pesquisa não acredita na neutralidade da ciência enquanto pressuposto epistemológico, mas se declara favorável ao distanciamento investigativo de modo a não se confundir o que realmente ocorre com conceitos prévios ou intenções valorativas do pesquisador.

A devolução dos resultados do estudo científico àqueles que foram pesquisados é algo esperado e às vezes até exigido pelos grupos, como no caso desta produção, que nos provoca reflexões a partir dos dados coletados junto ao grupo de pesquisa. Afinal é uma forma de perceberem que os resultados da pesquisa estarão ao seu dispor e poderão subsidiar o autoconhecimento do grupo e às ações em prol da melhoria de processos organizativos e de comunicação interna e externa. Não raro alguns grupos, tais como comunidades, grupos étnicos, organizações etc., se sentem como servindo apenas de "laboratório" para pesquisas acadêmicas ou mercadológicas. Respondem a entrevistas, se deixam ser observados, fotografados, filmados, mas não tem acesso aos resultados. Não é novidade para ninguém que, em geral o conhecimento gerado através de pesquisas retorne exclusivamente à "comunidade" científica, aos institutos de pesquisa ou às instituições que contrataram as pesquisas. Desse modo, também neste quesito a pesquisa-ação procura romper com os padrões vigentes. 
A parte empírica envolveu diálogos e discussões sobre concepções e práticas docentes (visões de educação, ensino, aprendizagem, (in)disciplina), leituras de livros, textos e relatórios de pesquisa que tratam da temática e/ou da abordagem metodológica da pesquisa-ação, entrevistas semiestruturadas, individuais e coletivas, análise de registros e documentos, observações e diário de campo, ao longo de 03 anos de trabalho.

Foram interlocutores desta investigação: orientadores e supervisores pedagógicos que atuam junto às escolas do município de Montenegro e professores que ministram aulas em quinta série do ensino fundamental; serão envolvidas 05 escolas do município, que têm quintas séries.

Plano de execução da pesquisa:

a) Trabalho com os orientadores e supervisores para discussão e estudos sobre a temática e a metodologia de pesquisa (reuniões quinzenais na Secretaria Municipal de Educação); organização e participação em palestra sobre a temática; primeiros contatos dos orientadores e supervisores com os docentes das quintas séries que aderiram à proposta; caracterização diagnóstica do contexto das escolas envolvidas; análise de registros e documentos das escolas e/ou utilizados pelos professores;

b) Reuniões com orientadores e supervisores, com dinâmicas diferenciadas para apropriação do referencial teórico-metodológico (reuniões mensais na Universidade), para preparação das intervenções junto aos professores e para análise dos achados; desenvolvimento das sessões de trabalho com os professores das quintas-séries; observação do trabalho realizado pelos supervisores e orientadores junto aos professores, com registro em diário de campo (no mínimo duas por escola); entrevistas individuais e ou grupais com orientadores e supervisores, sempre que necessário; participação em eventos regionais, nacionais e nacionais para socialização da experiência;

c) Elaboração de textos registrando a experiência; interlocução com instituições de ensino superior (especialmente com os cursos de formação de professores) e escolas da rede, envolvidas ou não na experiência, para socializar achados; participação em eventos científicos.

\section{Resultados das análises}

Esta temática, com múltiplas causas e efeitos, tem sido estudada algumas vezes sob enfoque psicológico, outras sob enfoque sociológico, mas nesse estudo pretendemos refletir sobre os aspectos pedagógicos, mesmo considerando os limites e restrições desse olhar. Pretendeu-se, para, além disso, entender melhor a temática, e conforme Santos "buscar alternativas de sociabilidade", alternativas democráticas que apontassem para 
horizontes de "emancipação", que neutralizassem o risco de erosão do contrato social (2000, p. 3). A partir das análises do grupo, deixou-nos, esta investigação, algumas certezas:

a) A escola é, de fato, um espaço rico de contradições;

b) Os sujeitos que aí habitam têm potencialidades, produzem saberes, que precisam ser reconhecidos em sua notoriedade;

c) A forma como o sistema escolar e/ou escola funciona pode ser facilitador ou dificultador de aprendizagem e desenvolvimento profissional;

d) Espaços e situações de reflexão e problematização compartilhados/coletivos facilitam o processo de desenvolvimento profissional, são formativos, mas podem ou não resultar em aprendizagem para a profissão;

e) O trabalho pedagógico continuado e a identificação dos benefícios do mesmo sobre as aulas e os alunos favorecem a aprendizagem e o desenvolvimento profissional;

f) A acolhida positiva e propositiva da equipe diretiva ao trabalho do professor, ouvindo-o e valorizando-o favorece o desenvolvimento a aprendizagens profissionais;

g) Nem sempre mudanças de representações e discursos dos professores são acompanhadas por mudanças nas práticas docentes;

h) As ações humanas, sistematizadas em torno de processos instituídos, como é o caso da educação escolarizada, sendo tributárias da concepção de Estado, são portadoras tanto de forças regulatórias como emancipatórias.

Este projeto inseriu-se na Linha de Pesquisa Prática Pedagógica e Formação do Educador e deu continuidade às investigações dos pesquisadores e do grupo de pesquisa na interlocução escola/universidade, a partir do olhar dos profissionais que atuam na Escola, ressignificando-a como espaço formativo privilegiado, por um lado, e qualificando a formação inicial, na Universidade, por outro. Sob esse ponto de vista, o estudo contextualiza as relações família e escola ao longo dos tempos, o conceito e a origem da disciplina/indisciplina na sociedade, alternativas de manejo e o olhar necessário sobre a indisciplina.

\section{Questões da indisciplina no contexto sócio-educacional}

No panorama mundial no que diz respeito à educação ocorreram três grandes revoluções que alteraram na raiz a forma de conceber e produzir a educação e o ensino. Segundo Brunner (2000), na primeira o ensino deixa de ser familiar e difuso para ser institucional e sistêmico, surgindo então à escola como espaço destinado ao ensino sistematizado. A segunda revolução surge com a criação dos sistemas escolares públicos, marcada pelo surgimento da ação do Estado no processo de transmissão do conhecimento e da cultura, passa-se do modelo religioso de administrar 
a escola para o modelo burocrático homogeneizante de controle administrativo. Simultaneamente ao surgimento da imprensa, esse período organiza a estrutura escolar em disciplinas e em níveis, e marca o surgimento do Código de Disciplina Escolar. A terceira revolução está ainda em desenvolvimento no Brasil e terá conseqüências vitais para a sociedade. Trata-se da revolução da educação massificada.

A educação no Brasil contempla a maioria das crianças e adolescentes no Ensino Fundamental, porém já não podemos afirmar o mesmo quanto ao Ensino Médio e Superior, que apesar dos esforços da legislação vigente na ampliação do Ensino Fundamental de oito para nove anos, com ingresso de alunos com idade de seis anos, favorecendo com isso a ampliação do atendimento na Educação Infantil, no Brasil estamos apenas começando a viver esse fenômeno da massificação da educação. O ser humano ao longo da vida passa por diferentes experiências, internalizando regras que são ditadas pelas diversas instituições pela qual transita. No entanto, nem todas as instituições transmitem de forma eficaz os regramentos, deixando lacunas a serem preenchidas, transferindo tal responsabilidade a outro grupo.

A família é o primeiro grupo que se organiza em volta do ser humano, disposto a impor as normas, as atitudes e orientações dos pais que servem de exemplo e estímulo a conduta dos filhos. Assim sendo, a família age como um fator de equilíbrio para um comportamento futuro das crianças e dos adolescentes. Os regramentos familiares colaboram aos ajustes futuros do comportamento social. A ausência de vínculos fortes e de regras definidas poderá dificultar a solução de problemas, criando outros para fora da família.

A escola passou a intervir de forma intensa na vida da família, tentando solucionar os conflitos gerados no ambiente familiar, refletidos nos comportamentos dos alunos na vida escolar. Tal situação trouxe um acréscimo de atribuições aos educadores para as quais não estavam preparados. A escola envolveu-se com a família, mas a família nem sempre se envolve com a escola, repassando quase por completo a obrigação da educação.

De acordo com Fischman e Torres (1996), uma família não é unicamente um sistema de apoio que proporciona ajuda; ela também pode ter importante função de resolver problemas. Entretanto, uma resolução de problemas efetiva freqüentemente envolve distinguir as coisas que é melhor fazer dentro da família e as coisas que é melhor fazer fora dela. Os pais, professores, profissionais de saúde e a igreja já não possuem mais "receitas" para educar crianças corretas, obedientes e responsáveis. A Pedagogia Tradicional que pretendia lapidar e para isso utilizava até mesmo o castigo, não consegue mais convencer as crianças. Concomitante com os modelos pedagógicos há todo um sistema político que foi sendo implantado e que necessita de uma educação que o legitime.

Identificamos certa tensão existente entre instituições: a família e a escola. A família que se encontra com outra configuração, atribui à escola a responsabilidade de educar bem seu filho e dar limites. A escola recebendo alunos muitas vezes indisciplinados, atribui a culpa aos pais. Essas instituições consideradas seguras encontram-se em crise, instituições que se concebiam como únicas responsáveis pela formação humana, estão angustiadas pela falta de referenciais. 
Em certas circunstâncias, o ato indisciplinado seria a manifestação de uma agressividade latente dirigida contra as figuras de autoridade, agressividade essa gerada pela "desestruturação" do ambiente familiar (a desagregação dos casais, a falta de tempo para cuidar dos filhos, a precária supervisão das tarefas escolares, etc). De modo genérico, supõe-se que as condutas dos alunos envolvidos em situações disciplinares sejam resultado de prejuízos psíquicos difusos, ligados à primeira infância e ao modo permissivo como tais crianças e adolescentes foram criados por suas famílias ou convivem em suas escolas.

Segundo La Taille (1998), disciplina remete a regras. Com efeito, a pessoa disciplinada segue determinadas regras de conduta. Logo, disciplina corresponde ao que chamamos de moral: o respeito por certas leis consideradas obrigatórias. Portanto, a pessoa indisciplinada transgride as leis que deveria seguir. A indisciplina pode, às vezes, vir em decorrência de bons motivos éticos. Se as regras não fazem sentido (e há muitas nas escolas) e se derivam de valores suspeitos (como subserviência cega à autoridade), a indisciplina pode se justificar eticamente. Há indisciplina eticamente válida e desobediência legítima, graças às quais, aliás, a sociedade acaba por evoluir. Mas pensemos agora nas formas de indisciplina que ferem as leis morais, estas definidas como garantia de respeito a direitos legítimos. Transgressões deste tipo também podem acontecer nas salas de aula, como por exemplo, as agressões verbais e físicas, ignorar a autoridade do professor em sala de aula, fingindo que não lhe ouve, não lhe vê ou que ele não existe. Para o autor, a distinção entre moral e ética é a seguinte: a moral refere-se às leis que normatizam as condutas humanas, e a ética corresponde aos ideais que dão sentido à vida, a moral visa responder a pergunta "Como devo agir?" e a ética, responder a pergunta "Como viver?"

Conforme Bernstein (1996), as escolas não podem ser consideradas como instituições neutras, que têm como propósito somente o ensino de habilidades e conteúdos teóricos aos novos membros de uma sociedade. Elas carregam mensagens ideológicas que produzem e reproduzem a consciência e a identidade das pessoas e traduzem, em discursos pedagógicos, as relações de poder existentes na sociedade como um todo. Entretanto, as escolas também podem contribuir para a transformação social na medida em que se proponham a questionar e subverter o texto pedagógico oficial. A influência da cultura institucional sobre o comportamento das pessoas que nela estão inseridas interfere na organização da disciplina de uma escola, uma vez que independente das características de cada pessoa, essa instituição influencia de forma importante a maneira como cada uma delas se comportam, a partir de seu ingresso.

\section{Gênesis da indisciplina: perspectiva docente}

Considerando a escola como um espaço pedagógico, comprometido com a educação de todos, nos deparamos muitas vezes, com encargos sociais ilimitados, no entanto, nos responsabilizamos e enfrentamos os constantes 
desafios. Repensar a indisciplina, num contexto sócio-político-educacional, nos faz rever preconceitos e conceitos em relação à reorganização das famílias, da sociedade e do sistema de educação.

Num âmbito escolar são muitas as faces geradoras de indisciplina, a partir da percepção docente podemos elencar alguns motivos preponderantes, como a crise que mudou os padrões familiares, trazendo os trabalhadores do campo para a cidade, inserindo a mulher no mercado de trabalho, ocasionando a transferência das responsabilidades necessárias à formação das crianças, que pertenciam à família para a escola, terceirizando as suas funções, refletindo assim em carências de todos os tipos: afeto, atenção, econômica...

Outra questão relevante é a insuficiência das políticas públicas diante das necessidades básicas da classe trabalhadora, que desvalorizam a função social da família e da escola. A mídia é outro fator significativo, o papel que exerce na sociedade atual, como uma das formadoras de opinião, ditando normas, atitudes, conceitos, modismos, etc., que influenciam na formação de novos valores, que refletem no comportamento de adultos, jovens e crianças.

Observando os alunos podemos destacar a necessidade de estabelecer limites que estimulem a maturidade, a motivação e a autoestima (por parte dos pais e professores). É necessário também, exercitar o diálogo como forma de escuta e esclarecimento das dificuldades, no sentido de estabelecer regras claras e firmes, incentivando a participação dos envolvidos no processo educativo (professores, pais e alunos), transformando as atitudes agressivas através do diálogo.

Em relação à prática docente podemos mencionar o despreparo das escolas de formação, que mantém currículos impregnados de práticas autoritárias, repressoras e rígidas que formam lideranças pouco preparadas e descomprometidas com a realidade atual. Essa fragilidade do currículo reflete no sentimento de solidão que o professor vivencia na sala de aula, que acarreta em insegurança, baixa estima, falta de motivação, atividades pouco integradoras e sem sentido, ao planejamento inadequado, na ausência de metas...

Soma-se a isso, a falta de apoio e a ausência de uma linha de ação do Sistema Educacional, busca de soluções "milagrosas e paliativas", falta de respeito e ética para com a classe e entre os docentes. Por último, temos a interpretação equivocada das Legislações vigentes (Constituição, LDB, ECA, Conselhos Tutelares...).

\section{Alternativas de manejo no cotidiano escolar}

Sendo a indisciplina um fator presente no cotidiano escolar, devemos buscar alternativas para o enfrentamento e prevenção de atitudes dessa natureza. Muitas são as possibilidades utilizadas pelos professores, no entanto, não eliminamos os referidos atos indisciplinares por parte dos alunos, porém com o uso de determinadas atitudes, posturas, exemplos e trabalhos pedagógicos, podemos minimizá-los. 
Entre as atitudes docentes que promovem efeitos positivos, podemos citar: delimitação de responsabilidades no processo de ensino e aprendizagem (família e escola); diálogo e trocas através de exemplos do cotidiano; busca de apoio junto a Equipe Diretiva; exercício do respeito mútuo; demonstrações de carinho e atenção aos alunos; criação de vínculos de amizade com os alunos ditos "indisciplinados", com o objetivo de conquistá-los, resgatando o seu interesse pelas aulas; observação individual e coletiva dos alunos; demonstração de tranquilidade e paciência, principalmente nos momentos de indisciplina, desviando a atenção da turma para outro assunto.

E quanto à postura dos educadores no intuito de prevenir situações indisciplinares, temos ainda o conhecimento da realidade e história do aluno, assim como a procura de suas qualidades; promoção do debate sobre a temática e o conhecimento do ponto de vista dos educandos e seus motivos; cumprimentos das combinações entre educador e educandos; diferenciação entre indisciplina e comportamento normal de uma criança (conversar, brincar, caminhar, etc.).

No que se refere ao trabalho pedagógico, podemos nos utilizar dos encontros com as famílias, através de reuniões, festas, gincanas, clubes de mães, campeonatos esportivos entre pais, oportunizando atividades diversificadas dentro e fora da sala de aula; trabalhando valores, hábitos de cortesia, direitos e deveres e refletindo sobre as atividades desenvolvidas.

\section{O desafio da indisciplina: um novo olhar}

O enfrentamento da indisciplina no ambiente escolar deve ser encarado como um desafio para todos os envolvidos no processo educacional, contrariando a postura contemporânea e remanescente da nossa história sócio-políticocultural. A partir do pensar sobre suas causas e como os professores lidam no seu cotidiano com a indisciplina lançamos alternativas e possibilidades a serem trabalhadas no universo escolar, a fim de encarar o desafio da indisciplina, como por exemplo, investir na atualização profissional dos professores através de cursos, palestras, estudos bibliográficos sobre o tema, pesquisa e troca de experiências no ambiente escolar e acadêmico. Através da busca de apoio, resgatando os papéis sociais da família, da escola e da sociedade, trocando o estigma da culpa pela responsabilidade.

Dentro do espaço escolar devemos disponibilizar a escuta e a discussão sobre o tema (indisciplina) com colegas, alunos e familiares, proporcionando atividades que desenvolvam a autoestima e o bom relacionamento entre todos, analisar e refletir sobre situações de indisciplina, a partir de exemplos atuais junto aos alunos, propondo técnicas e experiências que deram certo. É importante compreender a indisciplina como um desafio e não uma afronta pessoal, no entanto, é necessário conhecer os alunos e sua realidade, trabalhando com as diferenças (familiar, social, cultural 
e étnica), desenvolvendo o respeito mútuo, educando através do exemplo, investigando o significado das situações de indisciplina.

O trabalho docente que se esconde atrás de práticas solitárias e individualistas, deve buscar o apoio e a parceria dos seus pares, da equipe diretiva e outros setores da escola, deve investir no lazer, na cultura, no entretenimento, buscando um equilíbrio psicológico e espiritual, na tentativa de acompanhar as mudanças dos novos tempos. É essencial que o professor seja um otimista, dotado de paciência e comprometimento, pois para o exercício de sua profissão, é imprescindível a crença nos valores humanos como única forma de transformação comprometida com uma educação para a cidadania.

Hoje, comportadas ou não, todas as crianças tem direito a estudar. Antigamente as escolas selecionavam os alunos comportados e ficavam de fora aqueles que não se ajustavam ao comportamento desejado. Nesse caso disciplina era trazida de casa, era inclusive um pré-requisito para o ingresso na escola. Disciplina é um trabalho de todos na sala de aula, cada cultura escolar e cada atividade em sala de aula tem uma disciplina adequada ao seu desenvolvimento, dependendo da situação a melhor pode ser o silêncio, as crianças perguntando ou conversando entre si.

As crianças de hoje possuem dificuldades em respeitar os limites, mas nós adultos também. Entendemos os motivos da nossa "indisciplina", porque sabemos que para muitas pessoas a regularidade se tornou impossível. Mas, se nós não somos disciplinados, por que esperamos um comportamento regular das crianças, como se fosse uma coisa natural, espontânea, quase herdada. A disciplina deve ser vista ao mesmo tempo como fim e como meio, um fim porque podemos desenvolver atitudes como concentração, responsabilidade, interesse, transformando em ferramentas pessoais e de trabalho. E também um meio, instrumento sem o qual as coisas não acontecem ou acontecem fora do prazo.

De acordo com Piaget (1977), em seu livro "O Julgamento Moral na Criança", as crianças, mesmo as bem pequenas já tem valores como o gosto pelas regras, pela disciplina, pelo fazer bem feito e por se entregar a uma tarefa coletiva. Esse autor provou que é possível ver isso através das brincadeiras, e que o respeito entre os iguais promove o desenvolvimento da criança.

Para alunos da Educação Infantil, entre 02 e 05 anos, a brincadeira, a fantasia, as histórias são ótimas estratégias. A argumentação científica não funciona com os pequenos. O recurso lúdico soa sincero para a criança, porque é uma espécie de dramatização do assunto, uma elaboração simbólica da questão. Nessa idade, outro recurso possível é simplesmente, com habilidade, dar uma ordem e pedir que ela seja cumprida, nesse caso, é preciso deixar claro para a criança que há uma diferença entre ela e o adulto.

Já na idade entre 06 e 11 anos é interessante trabalhar disciplina como uma boa regra ou uma regra sem a qual, certas coisas não se desenvolvem bem. O convencimento se dá de forma empírica, com exemplos, discussão, não mais 
com o faz de conta. Uma coisa é o imaginário, outra é a própria negociação da regra. O problema do convencimento no seu sentido adulto é que ele supõe um pensamento hipotético dedutivo, mas crianças com menos de 12 anos não entendem esse pensamento. É preciso trabalhar com elas a própria construção das regras mais adequadas para uma determinada tarefa que se espera que realizem.

Regra, por fim, é algo que se constrói por consentimento. Deve-se combinar previamente que a não observação das regras implicará punições ou perdas, pois um dos motivos que nos levam a aderir à disciplina são as consequências de não nos entregarmos a ela. Convencer é diferente de impor.

Segundo Macedo (2004), a disciplina na escola não é questão de boa conduta, nem de formação trazida de casa. Disciplina se aprende e é do interesse de todo mundo, porque facilita a relação das pessoas com as coisas. Disciplina é uma questão de competência e não de valor. O pressuposto fundamental da exigência da disciplina escolar é o de que a conquista do saber é uma tarefa difícil, árdua e complexa. Para alcançá-lo, é preciso que haja consciência da importância desse saber para a vida e para a construção da sociedade.

\section{Considerações finais}

A disciplina não surge assim, das medidas disciplinadoras, mas como exigência da organização de toda a vida escolar, do desenvolvimento do projeto educativo da escola e da organização do trabalho escolar em um processo de formação do ser social responsável pela construção da sociedade. A disciplina no exercício de construção de um projeto pedagógico nos permite viver, como afirma Di Giorgio (1986), a aventura estranhíssima do homem em não se conformar com o mundo que está aí e querer criar um mundo diferente, que é a cultura, ato pelo qual ele vai do homo sapiens ao ser humano.

Formar o ser humano, portanto, é um processo que não pode ser garantido com a indisciplina dos educadores expressa na dispersão de esforços, na fragmentação do trabalho escolar, na perda de tempo com as pequenas "brigas" por questões pessoais ou caprichos nas relações entre professores e especialistas, entre os próprios professores e entre professores e alunos. Ao contrário, a construção de um projeto pedagógico que tenha como horizonte a formação do aluno, como sujeito de aspirações, pressupõe um redirecionar do fazer pedagógico, o que implica disciplina, conforme Silva (1997).

Contrariando o que muitos pensam, as causas da indisciplina não estão apenas no estudante e na educação que ele traz de casa. Ao achar que as soluções para o problema estão fora de seu alcance, a escola nega a responsabilidade que lhe cabe. Disciplina tem tanto a ver com a família quanto com a escola. Para os professores interessados em "ensinar" disciplina é necessário trabalhar com dedicação, assim o aluno que não tem disciplina pode perfeitamente 
aprender a ter. Aprender a resolver problemas por meio do diálogo, no entanto, não se dá de uma hora para outra, a criança aprende gradualmente, como resultado da reflexão contínua, da troca de pontos de vista e da coerência nos procedimentos empregados.

De acordo com Aquino (2002), é uma espécie de pacto de confiança, primeiro diga-me o que espera que faça e seja, para que eu possa esperar algo de você. Assim começamos a cultivar expectativas acerca do outro e de nós mesmos e passamos a contar com parâmetros de julgamento de nossas ações e das alheias. A polêmica sobre a disciplina e os limites na educação nos leva a repensar à busca de soluções únicas para manter alunos disciplinados, oriundos e imersos em universos tão diferentes. A pluralidade exige muito mais do professor. Ele deve recriar de acordo com os contextos, formas inteligentes de produzir consensos com as suas diversas turmas, sendo cada uma delas já o espaço das múltiplas diferenças.

Devemos enquanto educadores conscientizar-nos do desafio que temos pela frente, tendo bem claro que não existe um modo correto, mas sim o modo que encontramos de conseguir estabelecer alguns consensos mínimos e necessários com nossos alunos, deixando de lado os atritos entre família e escola, onde ambos procuram culpados, ao invés de buscarem os responsáveis. Acima de tudo, esta é uma luta e um desafio dos educadores, sejam eles professores, pais, enfim, pessoas comprometidas com as mudanças que nossa sociedade espera, e que urgentemente se fazem necessárias.

\section{Referências}

AQUINO, Julio Groppa. Pela ritualização da sala de aula. Revista Nova Escola, p. 14, jan.-fev. 2002.

AREND, Hannah. Entre o passado e o futuro. 2. ed. São Paulo: Perspectiva, 1979.

BERNSTEIN, Basil. Pedagogy, symbolic control and identity: theory, research, critique. London: Taylorand Francis, 1996.

BRUNNER, José J. Educação: Cenários de futuro. Novas tecnologias e sociedade da informação. Rio de Janeiro: PREAL, 2000.

CORREIA, José Alberto; MATOS, Manuel. Solidões e solidariedade nos cotidianos dos professores. Porto. Portugal: ASA Editores II, 2001.

FISCHMAN, G.; TORRES, C. A. Popular education: building from experiences. In: BROOKS, A.; WATKINS, K. (Ed.). Learning through action technologies. San Francisco: Jossey Bass, 1996.

FOUCAULT, Michel. Microfísica do poder. Rio de Janeiro: Graal, 1979.

FOUCAULT, Michel. Vigiar e punir: história da violência nas prisões. 10. ed. Petrópolis: Vozes, 1993.

FREIRE, Paulo; SHOR, Ira. Medo e ousadia: cotidiano do professor. 5. ed. São Paulo: Paz e terra, 1996. 
FREIRE, Paulo; FAUNDEZ, Antonio. Por uma pedagogia da pergunta. Rio de Janeiro: Paz e terra, 1985.

FREIRE, Paulo. Pedagogia da esperança. 3. ed. Rio de Janeiro: Paz e Terra, 1994.

FREIRE, Paulo. Pedagogia da autonomia. São Paulo: Paz e Terra, 1997.

FREIRE, Paulo. Pedagogia da indignação: cartas pedagógicas e outros escritos. São Paulo: UNESP, 2000.

FREIRE, Paulo. Pedagogia do oprimido. 11. ed. Rio de janeiro: Paz e Terra, 1982.

FREIRE, Paulo. Ação cultural para a liberdade. 3. ed. Rio e Janeiro: Paz e Terra, 1978.

GIORGIO, Cristiano Di. Escola nova. São Paulo: Ática, 1986.

MACEDO, Lino de. Ensaios pedagógicos: como construir uma escola para todos? Porto Alegre: ARTMED, 2004.

Minayo, M. C. de S. Pesquisa social: teoria, método e criatividade. 24. ed. Petrópolis, RJ: Vozes, 1994.

OLIVEIRA, Francisco de. Os direitos do antivalor. Petrópolis: Vozes, 1998.

PIAGET, Jean. O julgamento moral na criança. São Paulo: Mestre Jou, 1977.

SANTOS, Boaventura de Souza. A crítica da razão indolente: contra o desperdício da experiência. São Paulo: Cortez, 2000.

SILVA, Maria Aparecida da. Disciplina. Revista Presença Pedagógica, v. 3, n. 17, p. 86-91, set.-out. 1997.

TAILLE, Yves de La. Limites: três dimensões educacionais. São Paulo: Ática, 1998.

THIOLLENT. Michel. Metodologia da pesquisa-ação. 12. ed. São Paulo: Cortez, 2003.

Endereço para correspondência:

Glaé Corrêa Machado

Rua Menino Deus, 143 - Bairro Ferroviário

95780-000 Montenegro, RS, Brasil

<glaemachado@hotmail.com>

Recebido em: julho/2014

Aceito em: dezembro/2014 